\title{
O Escravo Urbano na Visão de um Viajante*
}

\section{Cláudio Pereira Elmir}

Especialmente no que respeita a Porto Alegre, é possível vislumbrar a significativa importância que assume o negro neste espaço urbano, quando lemos o livro de memórias de Josefh Hörmeyer: O Rio Grande do Sul de 1850. Descrição da Província do Rio Grande do Sul no Brasil Meridional.

Hörmeyer é um viajante alemão que visita a Província nos inícios da década de cincoenta, e que nos lega esta riquíssima obra, publicada originariamente na Alemanha, em 1854, cuja primeira edição em português é de apenas 1986.

Apesar de o objetivo da mesma ser a propaganda para a emigração de alemães e a sua vinda para o Rio Grande do Sul - o que transparece muito claro em todo o texto ${ }^{1}$ - Hörmeyer dedica um não desprezivel número de páginas ao escravo negro, inserido este na formação social gaúcha do século XIX.

A importância de seu livro, enquanto fonte documental, inscreve-se na possibilidade que nos faculta de lançar um olhar à sociedade porto-alegrense do século passado, a partir de um protagonista desta mesma história. Ou seja, é possível abstrair conclusões acerca da escravidão negra na capital da Província, desde os relatos de um homem que não compunha os quadros do poder dirigente local, o que, contudo, não significa que estivesse pouco identificado com este setor dominante.

* Agradecemos a Paulo Roberto Staudt Moreira, que gentilmente nos emprestou suas idéias, algumas das quais ousamos incorporar ao nosso texto. Ver sua excelente monografia "Entre o deboche e a rapina: escravismo, urbanizaçăo e resistência", Porto Alegre, UFRGS, janeiro de 1990. 
A leitura de Hörmeyer, enfim, permite-nos apreender algumas representações daqueles que habitaram a geografia da cidade. Quer dizer, o nosso interesse central, neste momento, é recuperar um pouco do cotidiano de Porte Alegre e do negro neste espaço, conscientes, não obstante, do quảo parcial e fragmentada é a fonte de que dispomos, assim. como as nossas conclusões o serão.

Se, por um lado, a sua obra é fundamentalmente um instrumento de propaganda à emigração, neste sentido extremamente questionada em termos da imagem idílica que formula acerca da Província, ${ }^{2}$ o fato de a escravidão ser um tema secundário na sua análise reforça a possibilidade de extrairmos dele algumas conjecturas mais espontâneas, menos premeditadas.

$\mathrm{Na}$ verdade, existe uma lógica do ver e do olhar ${ }^{3}$ em Hörmeyer. Podemos afirmar que o autor vê o escravo ainda que olhe o imigrante. $\mathrm{Ou}$ seja, apesar da intenção de olhar o alemão, involuntariamente o negro é visto.

Já na introdução, percebe-se claramente o quanto há de direcionado no olhar de Hörmeyer, quando fala da excelência das províncias meridionais do Brasil:

"[...]somente essas podem ser aconselhadas ao emigrante alemão. Estas regiões, situadas ao sul do trópico, pertencentes, como os países da Europa do sul e central, à zona temperada, com vias fluviais e portos, com um clima mais ameno e abençoadas em exagero com imensa fertilidade - sujeitas a uma Constituição que não cede à norte-americana em liberalidade [...] essas regiões oferecem [...] o gozo da maior liberdade junto com a certeza de um lucro seguro e abundante." (HÖRMEYER, 1986:16).

O clima contribui à fertilidade e longevidade da população (p.43), ao mesmo tempo em que a terra é ótima para a agricultura (p.41) e as doenças não se desenvolvem (p.42). O que o olhar do viajante estrangeiro nos impõe é a invenção do paraíso no sul do Brasil (p.44), uma terra em estado de natureza que precisa ser civilizada pela mão de seus patrícios; senão somente pelo ethos ativo, empreendedor, racional e habilidoso do estrangeiro (p.41, 64, 101), também pela pouca vontade de trabalhar 
(p.47), inércia (p.50), letargia, preguiça (p.51), displiscência (p.52), indolência (p.65) enfim do nativo. ${ }^{4}$

Outro aspecto bastante superestimado por Hörmeyer e que denota de forma clara o sentido publicitário de sua prosa pode ser observado quando este refere a receptividade do gaúcho em relação ao estrangeiro:

"[...] a hospitalidade do campeiro é aquela de Abraão, o patriarca, que corre ao encontro do estranho, rico ou pobre, pedindo que honre a sua casa; lava-lhe os pés, põe na mesa o melhor do que a casa dispõe e, quando o hóspede segue adiante, humildemente se desculpa por não ter estado em condições de servir melhor o senhor." (HÖRMEYER, 1986:71).

Este trecho é muito significativo da noção de olhar que apontamos acima. $\mathrm{O}$ autor não percebe a hospitalidade do gaúcho, mas a forja de maneira mais que artificial, mítica. Na leitura de um potencial emigrante, que vive precariamente e sofre toda a sorte de dificuldades, nada mais alentador do que a promessa de uma cidade de deus na terra. Contudo, mal sabia o imigrante que "o convite para uma visão do paraíso converte-se em pouco tempo numa temporada no inferno" (SÜSSEKIND, 1990:23). Enfim, existe uma tendência de significar a realidade do longínqüo de forma a não percebê-la em todas as suas nuances. $\mathrm{O}$ efetivo contato do estrangeiro com a pretensa "pátria de adoção"s demonstrou quão ficcional foi a hospitalidade daquele que recebeu o diferente.

Especificamente no que concerne à abordagem que empreende da escravidão, buscamos ressaltar a espontaneidade contida na sua visão desta instituição, diferentemente do olhar pensado que lança à imigração. Isto, contudo, não o exime de afirmar incongruências acerca do escravismo. Em primeiro lugar, deve-se ressaltar que o autor tem uma visão um tanto idílica da escravidão no sul do Brasil, o que se aproxima bastante da já tradicional e hoje fortemente contestada (veja-se a obra pioneira de CARDOSO, 1977) noção de "democracia racial". Para Hörmeyer: "De há muito é notório que os portugueses e seus descendentes foram os senhores mais brandos de escravos; isso vale, em especial, para os brasileiros onde reina entre senhores e escravos uma relação verdadeiramente patriarcal" (HÖRMEYER, 1986:78). 
O autor nos permite descernir comportamentos diferenciados do escravo em função do espaço específico que esteja ocupando no corpo social. Em outros termos, podemos perceber claramente que existem códigos distintos de comportamento para o negro, que a "casa" e a "rua" irão lhe prescrever. ${ }^{6}$

Em relação ao primeiro espaço referido, diz Hörmeyer: "Ainda agora é uso em todas as casas brasileiras e na maioria das alemãs que o serviçal livre de ambos os sexos toma suas refeições à mesa do patrão, enquanto somente o escravo toma sua refeição na cozinha ou num lugar separado" (HÖRMEYER, 1986:65). Ao mesmo tempo em que a casa e a rua demandam comportamentos diferentes, percebemos que no próprio interior destes dois espaços, existe uma certa hierarquização que distingue o livre do não-livre. Podemos afirmar, assim, que o espaço institui o comportamento, dando-lhe forma. Na casa, as relações escravistas assumem um caráter mais rígido, denotando que no espaço privado a noção de propriedade se fortalece.

A rua fornece uma outra imagem do status do negro. Por ser um espaço público, de maior indiferenciação entre as pessoas, é preciso criar outros sinais para determinar a categoria de escravos, distinguindo-o do homem livre e do liberto. "O sinal de distinção, consagrado pelo uso, entre o moreno livre e o escravo, consiste em que o último não pode usar calçado" (HÖRMEYER, 1986:79). Porém, é preciso atentar para o fato de que o escravo nem sempre respondeu passificamente a estes sinais de diferença. Referindo-se a um negro fugitivo, há um anúncio do jornal "Rio-Grandense" de 23 de abril de 1867 que descreve o crioulo João Antonio, de 26 anos, da seguinte maneira: "bonita figura, traja bem e anda calçado. Levou sobretudo de casimira usado, chapéo de aba larga" (citado por MOREIRA, 1990:44)

Assim, queremos crer que a rua constitui-se num espaço de maior autonomia do escravo em relação à propriedade de seu senhor. Parecenos que 0 escravo na rua assume uma relativa individualidade que 0 espaço privado da casa do senhor lhe obstaculiza. Será o espaço público - lugar da individuação, da autonomização de um "instrumento de trabalho"7 aqui transmutado em ser humano? Vejamos uma passagem esclarecedora de Hörmeyer:

"O rio-grandense é de um caráter extremamente bondoso e cavalheiresco, em que cortesia e hospitalidade 
são entrelaçadas indissoluvelmente. Em especial, as mulheres brasileiras são as que mais sentem essa cortesia, visto não terem afazeres nenhuns; até de manhã, o marido ou um escravo-negro vai à feira para as compras; aliás, todas as compras, mesmo num armazém, são de sua competência, porque raras vezes se vê que as brasileiras saem de casa. Daí vem o costume de os comerciantes a varejo irem com suas mercadorias, carregadas por um escravo, de casa em casa, à maneira de nossos mascates. $\mathrm{O}$ costume do país proíbe às mulheres brasileiras a se mostrar na rua sem acompanhante, assim como aos homens a carregar qualquer pacote, mesmo um livro, na rua; para isso existem os negros" (HÖRMEYER, 1986:65).

Fica clara nesta passagem uma das principais ocupações do escravo urbano: carregador; ${ }^{8}$ o que já foi demonstrado para a cidade do Rio de Janeiro por Luiz Carlos Soares (SOARES, 1988:107-142). O fato de o escravo carregar inclusive um livro demonstra o sentido negativo do trabalho, enquanto esfera dos desqualificados socialmente, ao mesmo tempo em que reforça a idéia de uma sociedade que se forjou sob a égide do parasitismo nobiliárquico (ver FAORO, 1984).

Por outro lado, este mesmo trecho nos coloca claramente que o limite de autonomia do escravo no espaço público é significativamente maior em relação àquele destinado à mulher das boas famílias. Se a presença do escravo na rua pode sugerir prestígio ao senhor, à de sua mulher, ao contrário, implica transgressão, aos olhos da família tradicional. Paulo Roberto Moreira, referindo-se à utilização por parte dos escravos, do nome de seus senhores para realizarem transações, cita um anúncio de jornal que ratifica as impressões do nosso viajante (MOREIRA, 1990:19):

"O abaixo assignado, tendo anunciado em 1853 que não se responsabilizava por dívidas feitas por seus escravos sem bilhete seu ou de sua mulher D. Ignácia Maria da Silva, torna de novo a anunciar que não se responsabiliza por semelhantes dívidas, por quanto nada compre fiado." (O Mercantil, $\mathrm{n}^{2} 30$, ano XIV, 6 de fevereiro de 1862).

Para Roberto da Matta, a rua é o lugar reconhecido e legitimado da fluidez, do movimento, da transgressão (DA MATTA, 1984:11/12). Em 
relação ao jogo do entrudo, em Porto Alegre, comenta Hörmeyer: "Aí não valem sexo, nem posição social, nem idade; todos devem acompanhar essa brincadeira ou fechar bem a casa e as janelas." (HÖRMEYER, 1986:77). O que está sugerindo o autor senão um processo de desierarquização que a rua incita? ${ }^{9}$

Raquel Rolnik nos fala em "apropriação simbólica do terreno público" (ROLNIK, 1988:25), expressão esta que nos parece compativel com a movimentação negra no espaço da cidade. As festas populares em Porto Alegre, notadamente as religiosas, ratificam esta noção, insinuando que o espaço público também é o local permitido da manifestação da voz do escravo e das camadas menos privilegiadas socialmente:

"Nos dias de festas altas, o respectivo "santo" é levado em procissão; pessoas mascaradas acompanhamno; são queimados fogos de artifício, tanto na véspera como no próprio dia da festa, não importando que, de dia claro e com céu luminoso, se estoure pólvora por uns 100 ou 1000 mil-réis, sem ter-se outro prazer a não ser estouro e fumaça. Esses fogos de artifício são custeados pela caixa da respectiva igreja e organizados por seus funcionários. Assim, no sábado de Aleluia é representada em Porto Alegre a Queima do Judas da maneira seguinte: na Rua da Praia são fincadas, de $20 \mathrm{em} 20$ metros, árvores em cujos galhos são penduradas figuras de homens e mulheres nos mais diversos trajes. Cabeça, braços, pernas e barrigas são embuchados com estopetas e cabeças-denegro; a um sinal dado, às 12 horas do meio-dia, é posto fogo, numa figura após outra, por um sacristão pardoamarelo, de aspecto muito venerável, e é realmente divertido de se ver como, sob o júbilo gritante da população negra que enche as ruas, ora um chapéu de panamá, ora uma coifa de uma vendedora de peixe, aqui uma bota de montar e lá uma anágua, estouram no ar" (HÖRMEYER, 1986:76). [destacamos].

Contudo, é preciso que não nos enganemos. A apropriação do espaço público não extingue as distâncias não-físicas que persistem na sociedade. Em outros termos, podemos afirmar que a indiferenciação física constitui-se numa estratégia para a manutenção das fronteiras sociais. Este áltimo trecho de Hörmeyer corrobora esta nossa impressão: 
${ }^{66}$ Os meios de conter uma tão numerosa massa de escravos que quase perfazem um terço de toda a população, oferece-os a Igreja Católica. Os muitos dias de festa, as procissões e fogos de artifício, ligados a isso, e os dias de descanso dos escravos destarte causados, fazem dos mesmos, sem que entendam muito daquilo, os mais fervorosos adeptos da Igreja unicamente salvadora; e raras vezes o cortejo de um dos Santos consta de menos de 2000 escravos de todas as matizes, a tagarelar e a gritar." (HÖRMEYER, 1986:79).

Quer dizer, o negro também está cumprindo um papel interessante à manutenção da ordem escravista nas suas manifestações na rua: respondendo positivamente à missão civilizadora e, mais do que isto, evangelizadora empreendida pela Igreja - ligada ao Estado Imperial. Ou seja, é preciso distender para reproduzir, alargar os espaços de relativa autonomia e individuação a fim de estender a dominação e fazer com que não sucumba a ordem social vigente. Estas estratégias de cooptação religiosa do negro comportam, assim, um duplo sentido: ao mesmo tempo em que constituem um espaço público de livre atuação do escravo, buscam enfraquecer as manifestações religiosas originais deste elemento - como os "batuques" e "candomblés", incorporando-o num órgão do Estado Imperial Escravista. ${ }^{10}$

Rolnik sintetiza brilhantemente estes duplos que a cidade carrega consigo, estas ambigüidades que são inerentes à estrutura da cidade lugar imune às irredutíveis dicotomizações: "Separa-se porque a mistura é conflituosa e quanto mais separada é a cidade, mais visível é a diferença, mais acirrado poderá ser o confronto" (ROLNIK, 1988:52). Porto Alegre, a partir da segunda metade do século passado, parece ter vivido a tensionada situação de uma paulatina negação do par senhor/escravo, no caminho de uma suposta "sociedade de pares".

\section{Notas}

1. Quanto a este aspecto em particular, há que considerar que o livro é produzido numa conjuntura imediatamente posterior ao conflito farrapo, momento este (1835-1845) de sensivel declínio na entrada de imigrantes ao estado (ver PICCOLO, 1989:62). Por outro lado, a obra prenuncia a proibição por parte da Prússia da imigração para São Paulo (Rescrito de Heydt-1859) e que será estendida para todo o país em 1871, haja vista as péssimas condições de vida a que serão colocados os imigrantes alemães. (DIÉGUES JR., 1964:46-7). 
2. Flora Süssekind, ainda que não o cite, nos faz pensar que Hörmeyer não é um viajante afeito às melhores letras: "Olhos de cientista, não há lugar para Eldorados na narrativa de um viajante ilustrado." SÜSSEKIND, 1990:142).

3. Inspiramo-nos em Sérgio Cardoso, em seu artigo "O Olhar do Viajante (do Etnólogo)", para estabelecer esta distinção entre o "ver" e o "olhar". Segundo o autor, o olhar perscruta, investiga, indaga, está direcionado, atento, tenso, alerta, possui impulso inquiridor; já o ver comporta a discrição, passividade, reserva, olho dócil, quase desatento (CARDOSO, 1989:347/351).

4. Esta oposição natureza (brasileira)/cultura (européia) pode ser verificada em textos de outros viajantes, como em Arsène Isabelle, por exemplo.

5. Esta điscutível expressão (ver crítica em ELMIR, 1990:18) é utilizada, por exemplo, em Lando \& Barros, 1982:58, para o caso da colonização alemã no Rio Grande do Sul.

6. Em relação à oposição casa/rua, ver os excelentes ensaios de Roberto da Matta (DA MATTA, 1987), a partir dos quais respaldamos nossa análise.

7. Devo dizer que não comungo com esta noção, que retira do escravo a sua condição irredutível de sujeito histórico, que reduz o seu espaço a um "elemento" apenas dentro de um determinado modo de produção.

8. Mais adiante, Hörmeyer expõe as atividades realizadas pelas escravas, numa clara referência à forma de trabalho servil típica do meio urbano, qual seja a de "escravos de ganho": "As escravas são empregadas, costumeiramente, como lavadeiras, vendedoras de frutas e em atividades semelhantes. Normalmente, o dono dá a seu escravo permissão para trabalhar na cidade por dinheiro; contudo, o mesmo deve entregar-lhe, cada tarde, uma ou uma e meia pataca [...]." (HÖRMEYER, 1986:78)

9. Esta festa popular, apesar de proibida pelo Conselho Geral da Província em 1834, mantem-se na capital da Província até a década de setenta do século passado, ao que tudo indica com a conivência da polícia. (Ver a expressão "CARNAVAL" em FRANCO, 1988:101/103.)

10. Em relação aos aspectos religiosos do escravo em Porto Alegre, nesta conjuntura, consultar MOREIRA, 1990:26/43.

\section{Bibliografia}

CARDOSO, Fernando Henrique. Capitalismo e Escravidão no Brasil Meridional. O negro na sociedade escravocrata do Rio Grande do Sul. 2.ed. Rio de Janeiro, Paz e Terra, 1977.

CARDOSO, Sergio. "O olhar viajante (do etnólogo)". In: O Olhar. São Paulo, Companhia das Letras, 1989. (p.347-60).

DA MATTA, Roberto. "Casa, Rua \& Outro Mundo. Reflexões sobre o espaço e a sociedade". In: Revista do Patrimônio Histórico e Artístico Nacional (19):5-14, 1984.

-. A Casa \& a Rua. Rio de Janeiro, Guanabara, 1987.

DIÉGUES JR., Manuel. Imigração, Urbanização, Industrialização. Rio de Janeiro, Instituto Nacional de Estudos Pedagógicos (MEC), 1964.

ELMIR, Cláuđio Pereira. "A Historiografia Gaúcha da Imigração: Um Exemplo de Abordagem Tautológica". Porto Alegre, UFRGS, agosto de 1990. p.21. [monografia xerografada]

FAORO, Raymundo. Os Donos do Poder. Formação do patronato político brasileiro. 6.ed. Porto Alegre, Globo, 1984. Vol. I.

FRANCO, Sérgio da Costa. Porto Alegre. Guia Histórico. Porto Alegre, Editora da UFRGS, 1988.

HÖRMEYER, Joseph. O Rio Grando do Sul de 1850. Descrição da Província do Rio Grande do Sul no Brasil Meridional. Porto Alegre, Luzzato/EDUNI-SUL, 1986. 
ISABELLE, Arsène. Viagem ao Rio do Prata e ao Rio Grande do Sul. Rio de Janeiro, Zélio Valverde, 1949.

LANDO, Aldair Marli \& BARROS, Eliane Cruxêm. A Colonização Alemã no Rio Grande do Sul. Uma interpretação sociológica. 2.ed. Porto Alegre, Movimento, 1982.

MOREIRA, Paulo Roberto Staudt. "Entre o deboche e a rapina: Escravismo, Urbanização e Resistência". Porto Alegre, UFRGS, janeiro de 1990. 53p. [monografia xerografada] PICCOLO, Helga Iracema Landgraf. "Escravidão, Imigração e Abolição." Considerações sobre o Rio Grande do Sul do Séc. XIX. In: Anais da VIII Reunião da Sociedade Brasileira de Pesquisa Histórica (SBPH). São Paulo, 1989. p.53-62.

ROLNIK, Raquel. O que é Cidade. São Paulo, Brasiliense, 1988.

SOARES, Luiz Carlos. "Os escravos de ganho no Rio de Janeiro do séc. XIX". In: Revista Brasileira de História, $\mathrm{n}^{\circ} 16$ (Escravidão). São Paulo, ANPUH/Marco Zero, 1988. p.107-42.

SÜSSEKIND, Flora. O Brasil não é longe daqui. O narrador, a viagem. São Paulo, Companhia das Letras, 1990. 